\title{
EFEITO DAAPLICAÇÃO DE SILICATO DE CÁLCIO EM Brachiaria rizantha CV. MARANDU SOBRE A POPULAÇÃO DE NINFAS DO PERCEVEJO CASTANHO DAS RAÍZES Scaptocoris carvalhoi BECKER, 1967, CARACTERÍSTICAS QUÍMICAS DO SOLO, PLANTA E PRODUÇÃO DE MATÉRIA SECA ${ }^{1}$
}

\author{
Application effect of calcium silicate in Brachiaria brizantha cv. Marandu on \\ the nymph population of the brown root stinkbug, soil chemical \\ characteristics, and plant and dry matter production
}

\author{
Elza Amélia de Souza ${ }^{2}$, Jair Campos de Moraes ${ }^{3}$, José Libério do Amaral ${ }^{4}$, \\ Ronaldo Dourado Liberato ${ }^{5}$, Emerson Alencar Bonelli ${ }^{6}$, Leni Rodrigues Lima ${ }^{6}$
}

\begin{abstract}
RESUMO
Neste trabalho, objetivou-se avaliar o efeito de diferentes doses de silicato de cálcio sobre a população de ninfas de percevejo castanho das raízes em Brachiaria brizantha, nas características químicas do solo, planta e produção de matéria seca. O experimento foi conduzido em blocos casualizados, com cinco tratamentos e quatro repetições, totalizando 20 parcelas. Os tratamentos testados foram cinco doses $\left(0,0,5,1,2\right.$, e $\left.4 \mathrm{t} \mathrm{ha}^{-1}\right)$ de silicato de cálcio aplicadas junto com a adubação NPK na implantação da $B$. brizantha. Foi avaliado o número de ninfas do percevejo (profundidade de 0 a $40 \mathrm{~cm}$ ), o pH e os teores de cálcio e de silício no solo. Aos 120 dias do plantio, a gramínea foi cortada, determinando-se a composição química e a produção de massa seca. Verificou-se que a aplicação de 2,6 $\mathrm{t} \mathrm{ha}^{-1}$ de silicato de cálcio foi a melhor dosagem estimada para a redução de ninfas do percevejo castanho das raízes. A aplicação de doses crescentes de silicato de cálcio no solo promoveu o incremento do $\mathrm{pH}$, dos teores de cálcio e silício no solo e o aumento na produção de matéria seca de $B$. brizantha.
\end{abstract}

Termos para indexação: Insecta, silício, poaceae.

\begin{abstract}
The objective of this study was to evaluate the effects of different calcium silicate rates on the nymph population of the brown root stinkbug in $B$. brizantha cv. marandu, in the soil chemical characteristics, and plant and dry matter production. The experiment was carried out in casualized blocks with five treatments and four repetitions, in a total of 20 plots. The treatments tested were five rates $\left(0,0.5,1,2\right.$, and $\left.4 \mathrm{t} \mathrm{ha}^{-1}\right)$ of calcium silicate applied together with NPK fertilization in the implantation of $B$. brizantha. The nymph number (depths 0 to $40 \mathrm{~cm}$ ), $\mathrm{pH}$, and soil calcium and silicon content were evaluated. On the 120th day after sowing, the grass was cut to determine the chemical composition and dry matter production. It was verified that the application of $2.6 \mathrm{t}$ ha ${ }^{-1}$ of calcium silicate was the best estimated rate for the reduction of brown root stinkbug nymphs. The application of increasing doses of calcium silicate in the soil caused an increase of the $\mathrm{pH}$, calcium and silicon content in the soil, and an increase in B. brizantha dry matter production.
\end{abstract}

Index terms: Insecta, Silicon, Poaceae.

(Recebido em 9 de abril de 2008 e aprovado em 6 de março de 2009)

\section{INTRODUÇÃO}

A popularidade e a aceitação entre os pecuaristas da Brachiaria brizantha cv. Marandu resultaram na implantação de extensas áreas dessa poácea no sistema de monocultivo. Tamanha adoção tornou o sistema de produção vulnerável aos estresses abióticos e ou bióticos capazes de reduzir a produtividade e a qualidade das forrageiras (Verzignassi \& Fernandes, 2001).

Os danos causados pela ação de insetos-praga são mais pronunciados em pastagens malnutridas, comparados

\footnotetext{
Parte da tese - Doutorado - Entomologia agrícola - UFLA - da primeira autora.

${ }^{2}$ Bióloga, Professora Doutora - Departamento de Ciências Biológicas - Universidade Federal de Mato Grosso - Rodovia MT 270 km 06 - $78700-000$ Rondonópolis, MT-sousa08@bol.com.br

${ }^{3}$ Agrônomo, Professor Doutor - Departamento de Entomologia - Universidade Federal de Lavras - Cx. P. 3037 - $37200-000$ - Lavras, MG jcmoraes@ufla.br

${ }^{4}$ Zootecnista, Professor Doutor - Departamento de Zootecnia - Universidade Federal de Mato Grosso/UFMT - Rodovia MT 270 km 06 - $78700-000$ Rondonópolis, MT - jlibério@terra.com.br

${ }^{5}$ Zootecnista, Mestrando em Ciência Animal - Faculdade de Agronomia e Medicina Veterinária - Universidade Federal de Mato Grosso - Rua Fernando Corrêa da Costa s/n, Coxipó - 78.060-900- Cuiabá, MT

${ }^{6}$ Graduandos em Zootecnia - Departamento de Zootecnia - Universidade Federal de Mato Grosso - Rodovia MT 270 km 06 - $78700-000$ - Rondonópolis,MT ebonelli02@ibest.com.br, lenirodrigues-zoo@yahoo.com.br
} 
a pastos com bom estado nutricional (Barbosa, 2006). Assim, é de se esperar que pastagens cujas plantas apresentem um sistema radicular profundo e vigoroso, explorando maior volume de solo, resistam mais ao ataque de pragas de hábitos subterrâneos (percevejo castanho, cupins e larvas de escarabeídeos) do que pastagens já degradadas (Valério, 2006).

No estado de Mato Grosso, a produção animal em pastagens tem sido limitada pelos insetos-praga e, dentre eles, destaca-se o percevejo castanho das raízes Scaptocoris carvalhoi Becker, 1967 (Hemiptera:Cydnidae), referido anteriormente na literatura como Atarsocoris brachiariae Becker, 1996. A classificação desta espécie foi corrigida por Grazia (2004), após revisão dos táxons neotropicais de escaptocoríneos, onde a autora observou que Atarsocoris brachiariae Becker, 1996 é sinônimo junior de Scaptocoris carvalhoi Becker, 1967. Esse percevejo ataca as raízes das gramíneas causando perda do valor nutricional e, consequentemente, a morte das plantas (Amaral et al., 1995). Este inseto tornou-se uma praga importante para as pastagens matogrossenses em razão da sua preferência por solos arenosos, nos quais sua locomoção é facilitada e é onde ocorre todo o seu ciclo biológico. É nesses solos que se verifica a maior expansão do cultivo de braquiárias (Amaral et al., 1996).

Os danos causados pelo percevejo S. carvalhoi em pastagens resultam da sucção de seiva das raízes, o que provoca perda de vigor das plantas; as folhas definham, secam e se tornam quebradiças. Como resultado, reduz-se consideravelmente a capacidade de suporte do pasto, sendo necessário, às vezes, fazer novo plantio (Medeiros, 2000).

As pastagens de $B$. brizantha, quando infestadas com 100 a 200 percevejos $/ \mathrm{m}^{2}$, têm apresentado baixa produção de matéria verde em resposta à adubação, e os bovinos têm apresentado baixo desempenho quanto ao ganho de peso, mesmo durante o período das chuvas (Souza et al., 2002).

O controle desse inseto é uma tarefa difícil, em função do hábito subterrâneo e ainda não existe um método eficiente para o seu controle. A utilização de inseticidas depara-se com problemas de ordem econômica e ecológica, o que tem direcionado os trabalhos de pesquisa para a avaliação de métodos alternativos de controle, como o preparo, a correção e a adubação do solo antes da implantação da pastagem (Amaral et al., 2000; Oliveira \& Sales Junior, 2002; Souza \& Amaral, 2003; Nakano, 2004).

A deposição de sílica na parede das células torna a planta mais resistente à ação de fungos e insetos. Isso ocorre pela associação da sílica com constituintes da parede celular, tornando-os menos acessíveis às enzimas de degradação (resistência mecânica) (Dayanandam et al., 1983). Alguns estudos demonstraram efeitos deletérios do silício ( $\mathrm{Si}$ ) sobre insetos-praga de importância econômica, como a lagarta-do-cartucho, pulgões e mosca branca (Carvalho, 1998; Goussain et al., 2002; Correa et al., 2005; Gomes et al., 2007). Dentre as gramíneas, inúmeras espécies são acumuladoras de $\mathrm{Si}$, com reflexos positivos na resistência das plantas a agentes bióticos e ou abióticos e na capacidade fotossintética (Deren, 2001; MA et al., 2001).

Geralmente, as decisões de uso do silício em plantas forrageiras estão baseadas na adaptação destas ao ambiente e à sua capacidade de produção de massa vegetal. A produção de matéria seca é comumente utilizada para inferir sobre o potencial de produção animal (Merchen \& Bourquin, 1994). Nesse conjunto, é importante entender qual o papel do $\mathrm{Si}$ em forrageiras no cerrado para que técnicas de manejo de solo, de forrageiras e de rebanhos obtenham proveito deste elemento e seu possível potencial de utilização (Korndörfer et al., 2002).

Os benefícios associados ao uso de silicatos estão relacionados não apenas ao fornecimento de $\mathrm{Si}$, mas também ao efeito dos mesmos como corretivos de acidez, fornecimento de Ca e Mg e também de micronutrientes (Queiroz, 2003).

No interior da planta, mais de $90 \%$ do total de $\mathrm{Si}$ acumulado encontra-se na forma de ácido silícico polimerizado, o qual é de difícil solubilização, e o restante encontra-se na forma coloidal ou iônica (Yoshida, 1981). Existem três locais reconhecidos de deposição de Si na planta: a parede celular, o lúmen celular e os espaços intercelulares nos tecidos das raízes, talos ou na camada extracelular da cutícula (Sangster et al., 2001).

Assim, objetivou-se, com a realização deste trabalho, avaliar o efeito de diferentes doses de silicato de cálcio sobre a população de ninfas de percevejo castanho das raízes em $B$. brizantha, nas características químicas do solo, planta e produção de matéria seca.

\section{MATERIAL E MÉTODOS}

O experimento foi conduzido, no período de março de 2005 a abril de 2007, na Fazenda Santa Ângela, numa área de $240 \mathrm{~m}^{2}$, localizada a $50 \mathrm{~km}$ de Rondonópolis, MT, na rodovia MT 130. As coordenadas geográficas são latitude $16^{\circ} 04^{\prime} 57.93^{\prime \prime}$ Sul, longitude 54⒊'26.13" Oeste e altitude de $523 \mathrm{~m}$. Esta área era anteriormente formada por pastagem de Brachiaria decumbens com cerca de seis anos.

Segundo Nimer (1989), o clima da região de Rondonópolis é do tipo quente com duas variações: na porção centro-sul é úmido com pouco déficit de água e três meses secos e ao norte, é semiúmido com moderado déficit de água e 4 a 5 meses secos.

O solo da área de estudo é um Neossolo Quartzarênico. Antes da implantação do experimento, foi realizada uma 
análise completa do solo que apresentou $86,5 \%$ de areia, $2,5 \%$ de silte e $11 \%$ de argila. Na semeadura, e, de acordo com a análise do solo, foi realizada uma adubação básica com a fórmula 4-30-10 (NPK), na dosagem de $250 \mathrm{~kg} \mathrm{ha}^{-1}$. Após 11 meses, foi realizada outra análise em cada parcela, sendo o solo coletado com um trado tipo caneca, na profundidade de $40 \mathrm{~cm}$, determinando-se o $\mathrm{pH}$ e os teores de cálcio, conforme metodologia da Embrapa (1999) e de silício, conforme Korndörfer et al. (2004).

O delineamento experimental foi em blocos casualizados, com cinco tratamentos e quatro repetições. Os tratamentos foram cinco doses $\left(0,0,5,1,2\right.$, e $\left.4 \mathrm{t} \mathrm{ha}^{-1}\right) \mathrm{de}$ silicato de cálcio, associadas ao adubo NPK no momento da implantação da B. brizantha. Cada bloco foi composto de cinco parcelas de $8,0 \mathrm{~m}^{2}$ e quatro repetições, totalizando 20 parcelas com área útil de $160 \mathrm{~m}^{2}$. A distância entre blocos foi de $2 \mathrm{~m}$ e $1 \mathrm{~m}$ entre parcelas.

Antes da implantação do experimento, foi realizada (em março/2005) uma contagem de ninfas do percevejocastanho em cada uma das parcelas, que foram demarcadas nesse período, para conhecer a população inicial na área. Posteriormente, foram feitas mais quatro avaliações, sendo uma em abril/2006 e as outras em fevereiro, março e abril de 2007. Todas as avaliações de ninfas foram realizadas no período de chuva de cada ano, pelo fato de esse inseto se encontrar numa menor profundidade no solo nesse período e se aprofundar no solo no período da seca, em busca de umidade. Para as avaliações, foi feita uma vala em cada parcela, com as dimensões de $20 \mathrm{~cm}$ de largura x $30 \mathrm{~cm}$ de comprimento $\mathrm{x}$ $40 \mathrm{~cm}$ de profundidade (Amaral et al., 1995).

Posteriormente, calculou-se a porcentagem de redução de ninfas, isto é, a porcentagem do número médio de ninfas após a aplicação dos tratamentos (média das quatro avaliações) em relação ao número inicial de ninfas antes dos tratamentos.

Antes do plantio da gramínea foi, aplicado, no final de agosto de 2005, um dessecante foliar na área. O plantio das gramíneas foi realizado na segunda quinzena de outubro de 2005, quando se iniciaram as chuvas. Em cada parcela, o adubo e os tratamentos, doses de $\mathrm{CaSiO}_{3}\left(23 \%\right.$ de $\mathrm{SiO}_{2} \mathrm{e}$ $36 \%$ de $\mathrm{CaO}$ ), foram aplicados a lanço e as sementes das gramíneas semeadas manualmente em oito linhas, com espaçamento de $25 \mathrm{~cm}$ entre elas, em cada parcela.

Aos 120 dias após o plantio, foram coletadas amostras da gramínea, utilizando-se uma moldura de madeira de $1 \mathrm{~m}^{2}$, que foi lançada ao acaso nas linhas centrais da parcela. As plantas do interior da moldura foram cortadas à altura de $25 \mathrm{~cm}$ do solo e acondicionadas em sacos de papel devidamente identificados. Em laboratório, o material foi colocado em estufa, a $60^{\circ} \mathrm{C}$, até a obtenção de peso constante determinando-se, então, a produção de matéria seca (MS). Posteriormente, as plantas foram trituradas em moinho de facas de inox, tipo Willey e armazenadas em frascos plásticos etiquetados. De cada frasco, foram retiradas amostras e levadas à estufa, a $105^{\circ} \mathrm{C}$, para então, determinar-se a composição química das plantas. Os teores de nitrogênio, fósforo, potássio, cálcio e magnésio foram determinados conforme metodologia de Malavolta et al. (1997) e o silício, conforme metodologia de Korndörfer et al. (2004).

Os dados foram submetidos à análise de variância e as médias comparadas pelo teste de Tukey, a 5\% de significância e análise de regressão para alguns parâmetros avaliados.

\section{RESULTADOS E DISCUSSÃO}

Observou-se (Figura 1) pela curva de regressão que uma aplicação de 2,6 $\mathrm{t} \mathrm{ha}^{-1}$ de silicato de cálcio provocou percentual máximo de redução da população de ninfas, em média, 63,54\% em relação ao tratamento sem silicato. Já para uma aplicação de 4,0 $\mathrm{t} \mathrm{ha}^{-1}$ de silicato de cálcio, maior dosagem testada, a redução estimada foi de apenas $45,04 \%$, em relação ao tratamento controle. Essa redução, no tratamento controle, pode ter ocorrido em razão de fatores edafoclimáticos ou ainda a menor disponibilidade de alimento durante a substituição de $B$. decumbens por B. brizantha.

Dessa forma, verifica-se eficiência do silicato na redução da população do percevejo castanho das raízes em $B$. brizantha. Uma possível causa da redução da população de ninfas é a indução de resistência das plantas ao inseto por barreiras mecânicas, em razão da deposição de silício na planta (Carvalho et al., 1999; Moraes \& Carvalho, 2002), ou químicas (Gomes et al., 2005).

Para o pH do solo, verificou-se (Figura 2) que houve resposta linear e crescente em função das doses de silicato de cálcio, promovendo aumentos de 0,145 unidades no $\mathrm{pH}$ do solo para cada $\mathrm{t} \mathrm{ha}^{-1}$ de silicato de cálcio aplicada. $\mathrm{O}$ aumento nos valores do $\mathrm{pH}$ do solo pela aplicação de silicato de cálcio ocorre em razão de suas propriedades corretivas (Faria, 2000; Pereira \& Korndörfer, 2003).

Pela equação de regressão (Figura 3), observou-se que à medida que aumentou a dose de silicato de cálcio, houve um acréscimo linear no teor de cálcio $(\mathrm{Ca})$ no solo. Assim, para cada t ha-1e silicato acrescido ao solo, há um aumento médio de $0,0812 \mathrm{mg} \mathrm{dm}^{-3}$ de cálcio. Em trabalhos realizados com o emprego de silicato de cálcio, como corretivo de solo, para produção de B. brizantha cv. Marandu (Sanches, 2003) e de capim-elefante (Vilela et al., 2007) os autores também relataram terem observado efeitos lineares e positivos do silicato de cálcio nos teores de Ca do solo. 


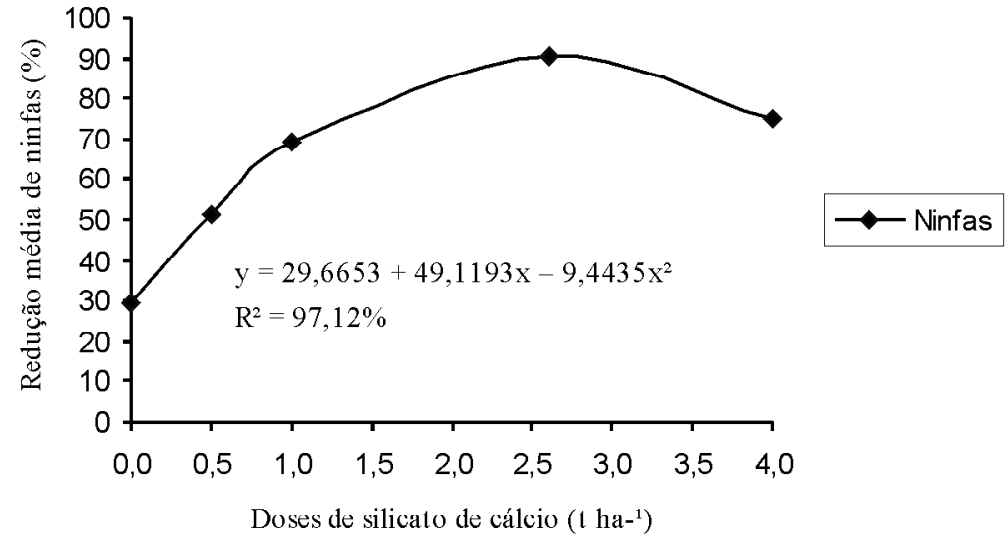

Figura 1 - Percentual de redução de ninfas do percevejo castanho das raízes $S$. carvalhoi, em função da aplicação de doses crescentes de silicato de cálcio em B. brizantha cv. Marandu. Rondonópolis (MT), 2007.

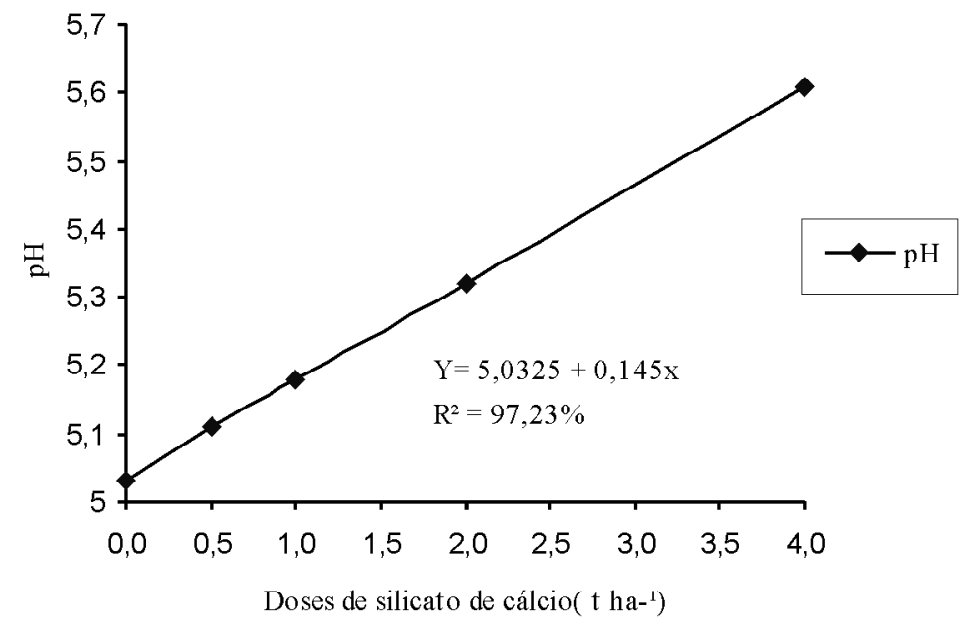

Figura 2 - Valores de pH do solo em função da aplicação doses crescentes de silicato de cálcio em B. brizantha cv. Marandu. Rondonópolis (MT), 2007.

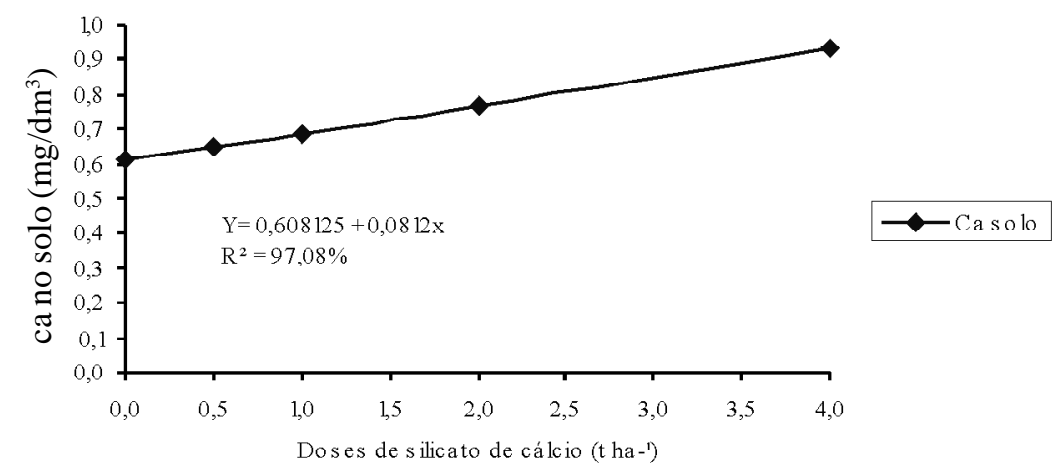

Figura 3 - Teores de cálcio no solo em função da aplicação de doses crescentes de silicato de cálcio em B. brizantha cv. Marandu. Rondonópolis (MT), 2007. 
Por outro lado, verificou-se (Figura 4) que a equação de regressão ajustada estimou uma dosagem de $3,40 \mathrm{t} \mathrm{ha}^{-1}$ de silicato de cálcio para um máximo de silício no solo $\left(1,58 \mathrm{dm}^{-3}\right)$. Considerando que a dosagem estimada de 2,6 t ha ${ }^{-1}$ está relacionada ao maior percentual de redução de ninfas do percevejo-castanho-das-raízes, isto corresponderia a um teor de $1,55 \mathrm{dm}^{-3}$ de silício no solo. $\mathrm{O}$ incremento nos teores de silício no solo pela adição de silicato de cálcio está de acordo com outras pesquisas envolvendo o Si (Korndörfer et al., 1999; Vilela et al., 2007).

Não se obteve um bom ajuste de modelos de equações para a composição química da parte aérea da $B$. brizantha, em função de aspectos biológicos relacionados à dinâmica de crescimento do capim. Dos modelos testados, regressão linear, raiz quadrada, quadrática, polinomial, etc., os $\mathrm{R}^{2}$ ficaram abaixo de $50 \%$. Dessa forma, optou-se pelo teste de médias, uma vez que, para a variável redução da população de ninfas, que é um dos fatores mais importantes deste trabalho, obtevese, pela análise de regressão, uma estimativa de $2,6 \mathrm{t} \mathrm{ha}^{-1}$ de silicato de cálcio, que é a dosagem que promove a redução máxima da população de ninfas. Portanto, com o teste de médias, foi possível verificar a significância das médias da composição química e da produção de massa da B. brizantha.

O valor médio da concentração de cálcio na parte aérea de $B$. brizantha (Tabela 1) variou de $1,65 \mathrm{~g} / \mathrm{kg}$ (testemunha) a $1,17 \mathrm{~g} / \mathrm{kg}\left(4,0 \mathrm{t} \mathrm{ha}^{-1}\right.$ de silicato de cálcio). É possível observar, ainda, que ocorreu redução significativa $(\mathrm{P}<0,05)$ da concentração de cálcio na planta de todas as doses de silicato em relação à testemunha, sendo de $4,84 \%, 20,0 \%, 24,24 \%$ e $29,26 \%$, respectivamente, para as doses de 0,$5 ; 1,0 ; 2,0$ e $4,0 \mathrm{t} \mathrm{ha}^{-1}$ de silicato de cálcio. As maiores doses do silicato promoveram menor concentração de cálcio e isso pode ter ocorrido pela diluição do cálcio nas plantas, que produziram mais massa seca (Tabela 2). Resultado semelhante foi observado por Melo (2005), que constatou efeito linear decrescente de doses de silício na concentração de cálcio em colmos e bainhas de $B$. brizantha.

Para o nitrogênio, verifica-se (Tabela 1) que o valor médio na parte aérea de $B$. brizantha variou de $12,60 \mathrm{~g} / \mathrm{kg}$ (testemunha) a 14,25 g/kg (2,0 t ha-1 de silicato de cálcio), valor este não significativo em relação à maior dosagem de silicato (4,0 t ha-1). Contudo, de acordo com Prado et al. (2007), pode não ocorrer resposta da aplicação de corretivos silicatados na concentração de nitrogênio nesta gramínea.
$\mathrm{O}$ valor médio da concentração de fósforo na parte aérea da $B$. brizantha (Tabela 1) variou de 1,02 g/ $\mathrm{kg}$ (testemunha) a $1,35 \mathrm{~g} / \mathrm{kg}\left(4,0 \mathrm{t} \mathrm{ha}^{-1}\right.$ de silicato de cálcio) que foi a maior resposta observada. Esse aumento de fósforo na parte aérea da planta pode ter ocorrido em razão do aumento no teor de silicato no solo, provocando reações químicas de troca de íons entre silicato e fosfato com a liberação do íon fosfato, aumentando assim o teor de fósforo na solução do solo, com consequente disponibilização à planta. Já, para a concentração de potássio, pode-se verificar, na mesma tabela, que a melhor resposta do uso de silício foi para a dosagem de 2,0 $\mathrm{t} \mathrm{ha}^{-1}$. Esses resultados confirmam os de Melo (2005) que observou efeitos positivos no fornecimento de silício no aumento na concentração de fósforo na parte aérea dessa gramínea. Contudo, diferem em relação à concentração de potássio naquela pesquisa, na qual não se observou resposta significativa de doses de silício.

Para o magnésio, pode-se observar (Tabela 1) resposta crescente da aplicação de silicato, com valor médio de $3,75 \mathrm{~g} / \mathrm{kg}$ na maior dose, sendo os resultados coerentes com os de Melo (2005). Quanto à concentração de silício na parte aérea da gramínea, também apresentou resposta crescente à adubação silicatada, semelhante a do magnésio, sendo de 1,25 g/ $\mathrm{kg}$ na maior dosagem testada do corretivo. De maneira geral, a resposta da adubação silicatada nas concentrações destes macronutrientes, em folhas e colmos de algumas gramíneas, tem sido crescente em função da dose (Melo, 2005; Vilela et al., 2007; Santos et al., 2007).

A produção de massa seca de $B$. brizantha (Tabela 2) variou de $28,56 \%$ (testemunha) a $29,56 \%\left(4,0 \mathrm{t} \mathrm{ha}^{-1} \mathrm{de}\right.$ silicato de cálcio). Demonstrando que a $B$. brizantha foi beneficiada pela aplicação de silicato de cálcio no momento do plantio. Esse efeito pode estar relacionado à interação com outros nutrientes que foram liberados à solução do solo com a correção do pH. Fato semelhante foi observado por Vilela et al. (2007), em capim-elefante, tendo a aplicação de silicato eliminado o alumínio tóxico e ainda disponibilizado quantidades suficientes de fósforo, magnésio e silício para a planta. Contudo, Fonseca et al. (2007) não obtiveram resposta linear crescente da aplicação de escória de siderurgia (fonte de $\mathrm{Si})$ na produção de massa seca de plantas de $B$. brizantha, sendo a curva ajustada quadrática, isto é, ocorreu um ponto ótimo e, posteriormente, decréscimo no desenvolvimento do capim. 


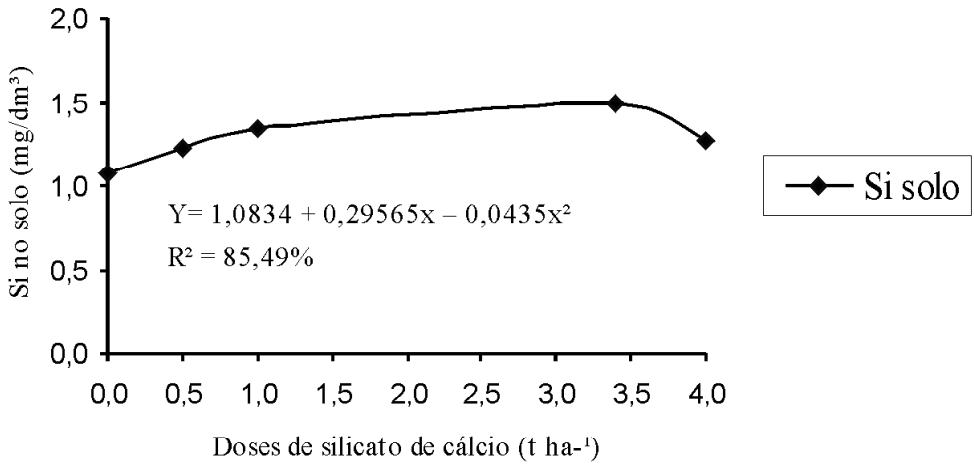

Figura 4 - Equação de regressão e curva para teores de silício no solo, para diferentes doses de silicato de cálcio em pastagem de B. brizantha cv. Marandu. Rondonópolis (MT), 2007.

Tabela 1 - Teores médios ( \pm erro padrão) dos macronutrientes cálcio $(\mathrm{Ca})$, nitrogênio $(\mathrm{N})$, fósforo $(\mathrm{P})$, potássio $(\mathrm{K})$, magnésio $(\mathrm{Mg})$ e silício ( $\mathrm{Si}$ ) na parte aérea da B. brizantha cv. Marandu, em solo submetido a diferentes doses de silicato de cálcio. Rondonópolis (MT), 2007.

\begin{tabular}{lcccccc}
\hline \multirow{2}{*}{ Tratamento } & \multicolumn{5}{c}{ Macronutrientes * } \\
\cline { 2 - 7 } & $\mathrm{Ca}$ & $\mathrm{N}$ & $\mathrm{P}$ & $\mathrm{K}$ & $\mathrm{Mg}$ & $\mathrm{Si}$ \\
\hline Testemunha & $1,65 \pm 0,004 \mathrm{a}$ & $12,60 \pm$ & $1,02 \pm$ & $13,78 \pm$ & $2,37 \pm$ & $0,91 \pm 0,004 \mathrm{e}$ \\
& $0,040 \mathrm{~b}$ & $0,0004 \mathrm{c}$ & $0,012 \mathrm{~d}$ & $0,002 \mathrm{e}$ & \\
& & & & & \\
Silicato de Ca $\left(0,5 \mathrm{t} \mathrm{ha}^{-1}\right)$ & $1,57 \pm 0,002 \mathrm{~b}$ & $13,12 \pm$ & $1,07 \pm$ & $13,78 \pm$ & $2,55 \pm$ & $1,02 \pm$ \\
& & $0,002 \mathrm{~b}$ & $0,002 \mathrm{c}$ & $0,006 \mathrm{~d}$ & $0,004 \mathrm{~d}$ & $0,0002 \mathrm{~d}$ \\
Silicato de Ca $\left(1,0 \mathrm{t} \mathrm{ha}^{-1}\right)$ & $1,32 \pm 0,004 \mathrm{c}$ & $13,30 \mathrm{a} \pm$ & $1,05 \pm$ & $14,67 \pm$ & $2,73 \pm$ & $1,05 \pm$ \\
& & $0,081 \mathrm{~b}$ & $0,004 \mathrm{c}$ & $0,002 \mathrm{c}$ & $0,004 \mathrm{c}$ & $0,0002 \mathrm{c}$ \\
Silicato de Ca $\left(2,0 \mathrm{t} \mathrm{ha}^{-1}\right)$ & $1,25 \pm 0,004 \mathrm{~d}$ & $14,25 \pm$ & $1,25 \pm$ & $15,42 \pm$ & $3,32 \pm$ & $1,12 \pm$ \\
& & $0,478 \mathrm{a}$ & $0,004 \mathrm{~b}$ & $0,002 \mathrm{a}$ & $0,002 \mathrm{~b}$ & $0,0002 \mathrm{~b}$ \\
Silicato de Ca $\left(4,0 \mathrm{t} \mathrm{ha}^{-1}\right)$ & $1,17 \pm 0,002 \mathrm{e}$ & $13,47 \pm$ & $1,35 \pm$ & $15,05 \pm$ & $3,75 \pm$ & $1,25 \pm$ \\
& & $0,002 \mathrm{ab}$ & $0,004 \mathrm{a}$ & $0,004 \mathrm{~b}$ & $0,004 \mathrm{a}$ & $0,0002 \mathrm{a}$ \\
\hline
\end{tabular}

* médias seguidas pela mesma letra, na coluna, não diferem entre si, pelo teste de Tukey (Pd"0,05).

Tabela 2 - Média ( \pm erro padrão) de matéria seca de $B$. brizantha cv. Marandu, em solo submetido a diferentes doses de silicato de cálcio. Rondonópolis (MT), 2007.

\begin{tabular}{lcc}
\hline \multicolumn{1}{c}{ Tratamento } & Massa seca $\left(\mathrm{t} \mathrm{ha}^{-1}\right)$ & Massa seca $(\%)^{*}$ \\
\hline Testemunha & 10,424 & $28,56 \pm 0,002 \mathrm{e}$ \\
Silicato de Ca $\left(0,5 \mathrm{t} \mathrm{ha}^{-1}\right)$ & 12,307 & $28,98 \pm 0,004 \mathrm{~d}$ \\
Silicato de Ca $\left(1,0 \mathrm{t} \mathrm{ha}^{-1}\right)$ & 12,955 & $29,03 \pm 0,006 \mathrm{c}$ \\
Silicato de Ca $\left(2,0 \mathrm{t} \mathrm{ha}^{-1}\right)$ & 13,764 & $29,36 \pm 0,002 \mathrm{~b}$ \\
Silicato de Ca $\left(4,0 \mathrm{t} \mathrm{ha}^{-1}\right)$ & 13,866 & $29,56 \pm 0,002 \mathrm{a}$ \\
\hline * médias seguidas pela mesma letra, na coluna, não diferem entre si, pelo teste de Tukey (Pd”0,05).
\end{tabular}

\section{CONCLUSÃO}

O silicato de cálcio foi eficiente em reduzir a população de ninfas do percevejo-castanho-das-raízes, aumentar os teores de cálcio, silício e pH do solo; aumentar os teores de nitrogênio, potássio, magnésio e silício na parte aérea da planta e incrementar a produção de massa seca do capim $B$. brizantha $\mathrm{cv}$. Murundu. 


\section{AGRADECIMENTOS}

À Coordenação de Aperfeiçoamento de Pessoal de Nível Superior (CAPES), pela concessão de bolsa de estudos.

\section{REFERÊNCIAS BIBLIOGRÁFICAS}

AMARAL, J.L.; BORGES, V.; SOUZA, J.R.; MEDEIROS, M.O. Efeitos dos tipos de preparação do solo e dos modelos alternativos de formação de pastagens no controle do percevejo castanho (Scaptocoris castanea Perty, 1830). In: REUNIÃO ESPECIAL DA SOCIEDADE BRASILEIRA PARA O PROGRESSO DA CIÊNCIA, 2., 1995, Cuiabá. Anais... Cuiabá: SBPC, 1995. p.283.

AMARAL, J.L.; MEDEIROS, M.O.; OLIVEIRA, C.; BORGES, V.; SOUZA, J.R. Utilização de calcário, gesso e NPK na renovação de pastagens em solos arenosos e ácidos, visando o controle do percevejo castanho das raízes Atarsocoris brachiariae Becker, 1996. In: SIMPÓSIO SOBRE RECURSOS NATURAIS E SÓCIO ECONÔMICOS DO PANTANAL, 2., 1996, Corumbá. Anais... Corumbá: Embrapa/SPI, 1996. p.145-146.

AMARAL, J.L.; MEDEIROS, M.O.; OLIVEIRA, E.A.S.; OLIVEIRA, C.; FERNANDES, L.M.S. Efeito de inseticidas sistêmicos e não sistêmicos misturados no adubo no controle do percevejo castanho das raízes. In: REUNIÃO DE PESQUISA DE SOJA DA REGIÃO CENTRAL, 22., 2000, Cuiabá. Anais... Cuiabá: Embrapa, 2000. p.69-70.

BARBOSA, R.A. Mortalidade de plantas forrageiras em pastagens nas regiões Centro-Oeste e Norte do Brasil: introdução ao problema. In: BARBOSA, R.A. (Ed.). Morte de pastos de braquiárias. Campo Grande: Embrapa Gado de Corte, 2006.

CARVALHO, S.K.; MORAES, J.C.; CARVALHO, J.G. Efeito do silício na resistência do sorgo (Sorghum bicolor) ao pulgão-verde Schizaphis graminum (Rond.) (Hemiptera: Aphididae). Anais Sociedade Entomológica do Brasil, Jaboticabal, v.28, p.515-510, 1999.

CARVALHO, S.P. Efeito do silício na indução de resistência do sorgo ao pulgão-verde Schizaphis graminum (Rondani, 1852) (Homoptera: Aphididae). 1998. 43p. Dissertação (Mestrado em Entomologia)Universidade Federal de Lavras, Lavras, 1998.

CORREA, R.S.B.; MORAES, J.C.; AUAD, A.M.; CARVALHO, G.A. Silicon and Acibenzolar-S-methil as resistance inducers in cucumber against the whitefly Bemisia tabaci (Gennadius) (Hemiptera: Aleyrodidae) Biotype B. Neotropical Entomology, Londrina, v.34, n.3, p.429-433, 2005.

DAYANANDAM, P.; KAUFMAN, P.B.; FRAKIN, C.I. Detection of silica in plants. American Journal Botany, Madison, v.70, p.1079-1084, 1983.

DEREN, C. Plant genotype, silicon concentration, and silicon related responses. In: DATNOFF, L.E.; SNYDER, G.H.; KORNDÖRFER, G.H. Silicon in Agriculture. Amsterdam: Elsevier, 2001. chap.8, p.149-158.

\section{EMPRESA BRASILEIRA DE PESQUISA} AGROPECUÁRIA. Manual de análises químicas de solos, plantas e fertilizantes. Brasília: Embrapa, 1999. 370p. (Comunicação para Transferência de Tecnologia).

FARIA, R.J. Influência do silicato de cálcio na tolerância do arroz de sequeiro ao déficit hídrico do solo. 2000. 47p. Dissertação (Mestrado)-Universidade Federal de Viçosa, Viçosa, 2000.

FONSECA, I.M.; PRADO, R.M.; NOGUEIRA, T.A.R.; SOUZA, F.V.; ROMUALDO, L.M. Produção de massa seca de plantas de Brachiaria no segundo corte em função da aplicação de escória de siderurgia, calcário e nitrogênio. In: SIMPÓSIO BRASILEIRO SOBRE SILÍCIO NA AGRICULTURA, 4., 2007, Botucatu. Anais... Botucatu: UNESP/FCA, 2007. p.22-25.

GOMES, F.B.; MORAES, J.C.; SANTOS, C.D.; ANTUNES, C.S. Silício: elemento mineral indutor de resistência em batata inglesa a Mysus persicae (Sulzer) Hemíptera: Aphididae). In: SIMPÓSIO BRASILEIRO SOBRE SILÍCIO NA AGRICULTURA, 4., 2007, Botucatu. Anais... Botucatu: UNESP/FCA, 2007. p.51-54.

GOMES, F.B.; MORAES, J.C.; SANTOS, C.D.; GOUSSAIN, M.M. Resistance induction in wheat plants by silicon and aphids. Scientia Agrícola, Piracicaba, v.62, n.6, p.547-551, 2005 .

GOUSSAIN, M.M.; MORAES, J.C.; CARVALHO, J.G.; NOGUEIRA, N.L.; ROSSI, M.L. Efeito da aplicação de silício em plantas de milho no desenvolvimento biológico da lagarta-do-cartucho Spodoptera frugiperda (J. E. Smith) (Lepdoptera: Noctuidae). Neotropical Entomology, Londrina, v.31, n.2, p.305-310, Apr./June 2002. 
GRAZIA, J.; SCHWERTNER, C.F.; SILVA, E.J.E. Arranjos taxonômicos e nomenclaturais em Scaptocorini (Hemiptera: Cydnidae, Cephalocteinae). Neotropical Entomology, Londrina, v.33, n.4, p.511-512, 2004

KORNDÖRFER, G.H.; ARANTES, V.A.; CORREAA, G.F.; SNYDER, G.H. Efeito do silicato de cálcio no teor de silício no solo e na produção de grãos de arroz de sequeiro. Revista Brasileira de Ciência do Solo, Campinas, v.23, p.623-629, 1999.

KORNDÖRFER, G.H.; PEREIRA, H.S.; CAMARGO, M.S. Silicatos de Cálcio e Magnésio na agricultura. 2.ed. Uberlândia: GPSi/ICIAG/UFU, 2002. 24f. (Boletim Técnico, 1).

KORNDÖRFER, G.H.; PEREIRA, H.S.; NOLLA, A. Análise de silício: solo, planta e fertilizante. Uberlândia: GPSi/ICIAG/UFU, 2004. 24f. (Boletim Técnico, 3).

MA, J.F.; MIYAKE, Y.; TAKAHASHI, E. Silicon as a beneficial element for crop plants. In: DATNOFF, L.E.; SNYDER, G.H.; KORNDÖRFER, G.H. (Eds.). Silicon in agriculture. Netherlands: Elsevier Science, 2001.

MALAVOLTA, E.; VITTI, G.C.; OLIVEIRA, S.A. Avaliação do estado nutricional das plantas: princípios e aplicações. 2.ed. Piracicaba: Potafos, 1997. 319p.

MEDEIROS, M.O. Influência dos fatores climáticos na dinâmica populacional do percevejo castanho Atarsocoris brachiariae. 2000. 129p. Dissertação (Mestrado em Agricultura Tropical)-Universidade Federal de Mato Grosso, Cuiabá, 2000.

MELO, S.P. Silício e fósforo para estabelecimento do capim-Marandu num Latossolo Vermelho-Amarelo. 2005. 110p. Tese (Doutorado em Solos e Nutrição de Plantas)-Universidade Estadual Paulista "Júlio de Mesquita Filho", Piracicaba, 2005.

MERCHEN, N.R.; BOURQUIN, L.D. Process of digestion and factors influencing digestion of forage-based diets by ruminants: section IV: role of digestion and metabolism in determining forage quality. In: FAHEY JUNIOR, G.C.; COLLINS, M.; MERTENS, D.R.; MOSER, L.E. Forage quality, evaluation and utilization. Madison: ASA/CSA/SSSA, 1994. chap.14, p.564-612.

MORAES, J.C.; CARVALHO, S.P. Indução de resistência em plantas de sorgo Sorghum bicolor (L.) Moench. ao pulgão-verde Schizaphis graminum (Rond., 1952)
(Hemiptera: Aphididae) com a aplicação de silício. Ciência e Agrotecnologia, Lavras, v.26, n.6, p.1185-1189, 2002.

NAKANO, O. Ainda ameaçador. Cultivar, Curitiba, v.58, p.18-21, 2004.

NIMER, E. Climatologia do Brasil. Rio de Janeiro: FIBGE, 1989. 421p.

OLIVEIRA, C.; SALES JUNIOR, O. Utilização de diferentes técnicas para o manejo do percevejo castanho Atarsocoris brachiariae Becker, 1996. Biodiversidade, Rondonópolis, v.1, p.110-115, 2002.

PEREIRA, H.S.; KORNDÖRFER, G.H. Fontes de silício para as plantas. In: SIMPÓSIO BRASILEIRO SOBRE SILÍCIO NA AGRICULTURA, 2., 2003, Lavras. Anais... Lavras: UFLA, 2003. CD-ROM.

PRADO, R.M.; FONSECA, I.M.; NOGUEIRA, T.A.R.; ROMUALDO, L.M.; SOUZA, F.V. Absorção de nitrogênio em Brachiaria brizantha no segundo corte cultivada em solo tratado com calcário, escória de siderurgia e nitrogênio. In: SIMPÓSIO BRASILEIRO SOBRE SILÍCIO NA AGRICULTURA, 4., 2007, Botucatu. Anais... Botucatu: UNESP/FCA, 2007. p.14-17.

QUEIROZ, A.A. Reação de fontes de silício em quatro solos do cerrado. 2003. 39p. Monografia (Graduação em Agronomia)-Instituto de Ciências Agrárias, Universidade Federal de Uberlândia, Uberlândia, 2003.

SANCHES, A.B.P. Efeitos do silicato de cálcio nos atributos químicos do solo e planta, produção e qualidade em capim - braquiarão [Brachiaria brizantha (Hoechst ex A. Rich.): Stapf. Cv. Marandu] sob intensidades de pastejo. 2003. 140p. Dissertação (Mestrado em Qualidade e Produtividade Animal)Universidade de São Paulo, Pirassununga, 2003.

SANGSTER, A.G.; HODSON, M.J.; TUBB, H.J. Silicon deposition in higher plants. In: DATNOFF, L.E.; SNYDER, G.H.; KORNDÖRFER, G.H. Silicon in Agriculture. Amsterdam: Elsevier, 2001. chap.5, p.85-113.

SANTOS, D.S.; SOUSA, R.T.X.; KORNDÖRFER, G.H. Avaliação do desenvolvimento do arroz (Oryza sativa) em um Neossolo do Triângulo Mineiro pela aplicação de doses de calcário e wollastonita. In: SIMPÓSIO BRASILEIRO SOBRE SILÍCIO NA AGRICULTURA, 4., 2007, Botucatu. Anais... Botucatu: UNESP/FCA, 2007. p.67-69. 
SOUZA, E.A.; AMARAL, J.L. Efeito do sistema de preparação do solo e da diversificação de gramíneas sobre a população de ovos de Atarsocoris brachiariae Becker, 1996. Biodiversidade, Rondonópolis, v.1, n.2, p.99-119, 2003.

SOUZA, E.A.; AMARAL, J.L.; MEDEIROS, M.O.; BOLOGNEZ, C.A.; BORSONARO, A.M.; KIMURA, M.T.; ARRUDA, N.V.M. Efeito do sistema de preparação do solo e da diversificação de gramíneas sobre a população adulta de Atarsocoris brachiariae Becker, 1996.

Biodiversidade, Rondonópolis, v.1, n.1, p.12-27, 2002.

VALÉRIO, J.R. Considerações sobre a morte de pastagens de $B$. brizantha cultivar Marandu em alguns estados do Centro-Oeste e Norte do Brasil, Enfoque entomológico. In: BARBOSA, R.A. (Ed.). Morte de pastos de braquiárias. Campo Grande: Embrapa Gado de Corte, 2006.

VERZIGNASSI, J.R.; FERNANDES, C.D. Doenças em forrageiras. Campo Grande: Embrapa Gado de Corte, 2001. 3p. (Embrapa Gado de Corte. Gado de Corte Divulga, 50).

VILELA, H.; ANDRADE, R.A.; VILELA, D. Efeito de níveis de silicato sobre a correção do solo, produção e valor nutritivo do capim elefante paraíso (Pennisetum hybridum). In: SIMPÓSIO BRASILEIRO SOBRE SILÍCIO NA AGRICULTURA, 4., 2007, Botucatu. Anais... Botucatu: Unesp/FCA, 2007. p.9-13.

YOSHIDA, S. Fundamental of rice crop science. Los Banos: International Rice Research Institute, 1981. 